\title{
Langerhans Cell Histiocytosis of the Tonsil
}

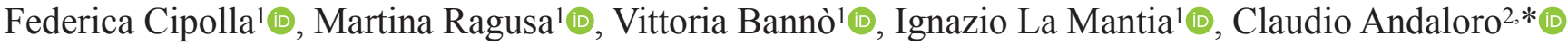

\author{
${ }^{1}$ Department of Medical Sciences, Surgical and Advanced Technologies, GF Ingrassia, University of Catania, Catania, Italy \\ ${ }^{2}$ Department of Surgery, Otolaryngology Unit, Latisana-Palmanova Hospital, Azienda Sanitaria Universitaria Friuli Centrale (ASUFC), Udine, Italy
}

Langerhans cell histiocytosis $(\mathrm{LCH})$ is a rare disease that is characterized by clonal neoplastic proliferation of the dendritic Langerhans cells. LCH presents either with solitary or multiple organ involvement. ${ }^{1,2}$ The most commonly affected organs include the bones, skin, and pituitary gland; the hematopoietic system, lymph nodes, and lungs are rarely affected. ${ }^{3}$ Tonsillar involvement is extremely rare. We report the case of a 36 -year-old female patient with unusual unilateral tonsillar palatine involvement of LCH. The patient complained of pharyngeal foreign body sensation, earache, and worsening difficulty in swallowing for approximately 4 months. She had no other symptoms like voice changes, neck pain or stiff neck, and headache. She had no previous medical history and did not take medications. Physical examination showed an enlargement of the left palatine tonsil, covered by purulent exudate with ulceration with a raised edge (Figure 1a), and a left submandibular lymph node enlargement of approximately $1 \mathrm{~cm}$. No alterations were found in the blood sample, but skin lesions were present, which appeared diffused, papular, and exfoliative, similar to seborrheic dermatitis lesions (Figure 1b), and were located in the torso and limbs. An incisional biopsy of the tonsil and lymph node was performed. Histopathological examination of the tonsil specimen revealed histiocyte-like cell infiltration with pale eosinophilic cytoplasm, irregular and elongated nuclei, and indistinct nucleoli. S-100, CD68, CD1a, and fascin were positive without immunoreactivity for PAX5 and CD20n, and the Ki-67 proliferation index was $10 \%$ in immunocytochemical staining (Figure 2). A reactive lymphocytic proliferation was seen in the lymph node specimen. The computed tomography scans of the neck, thorax, and abdomen did not detect any further disease manifestations. She was treated with cladribine at $10 \mathrm{mg} / \mathrm{d}$ subcutaneously for 5 days every 3 weeks for four cycles. At the 1-month follow-up, the patient showed significant improvement with tonsillar and skin lesion disappearance (Figure 1c) and a remarkable lymphadenopathy volume reduction. After four cycles, the last two reduced doses achieved complete remission.
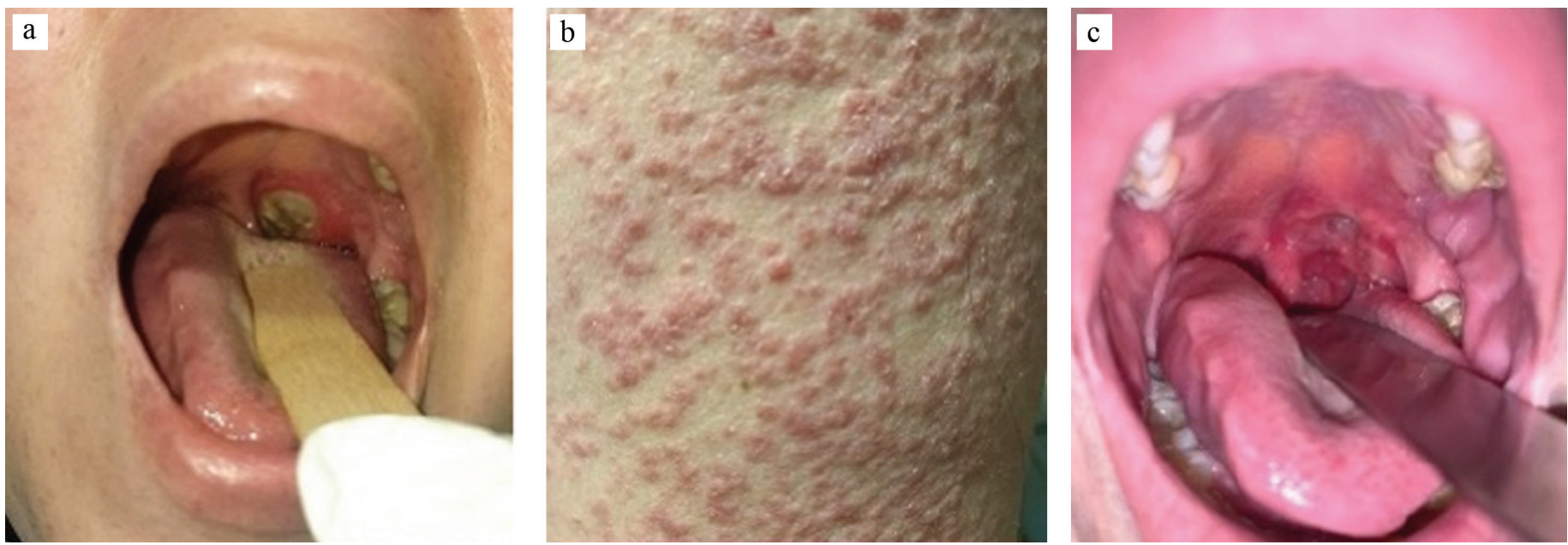

FIG 1 a-c. Ulceration with a raised edge over the left palatine tonsillar region with surrounding erythema (a). Seborrheic dermatitis-like skin lesions over the limbs and torso (b). The posttreatment clinical image of the left palatine tonsillar region at the end of the 1-month follow-up (c).

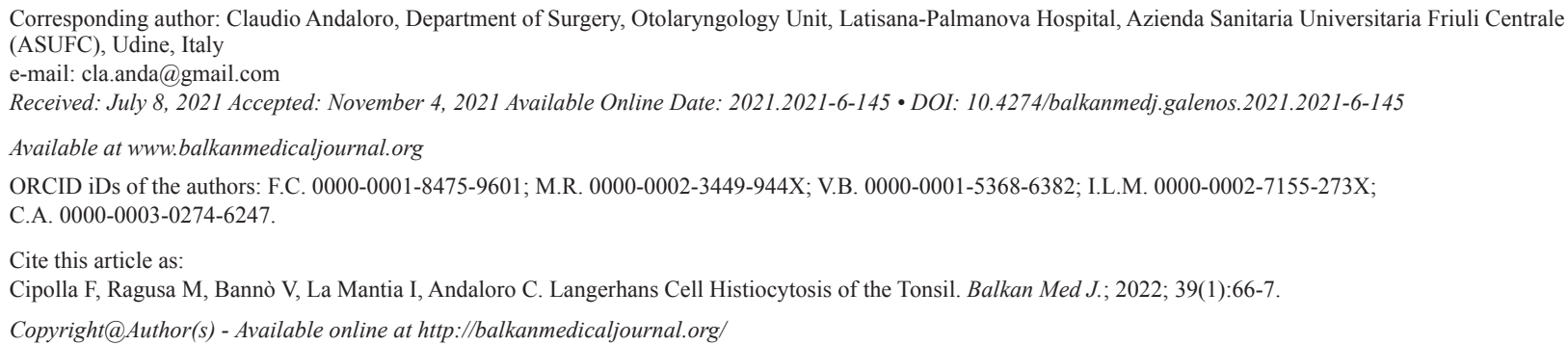



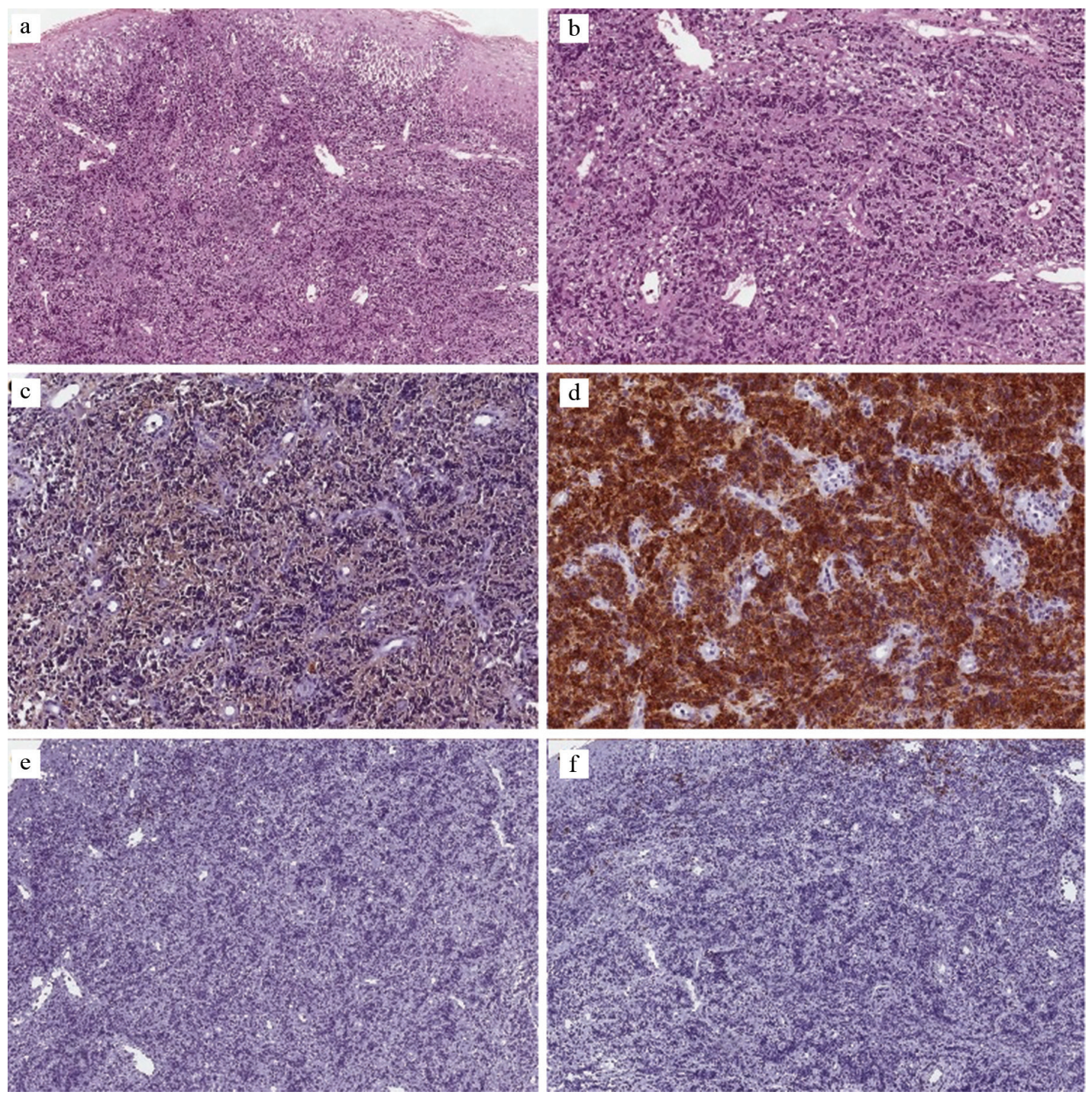

FIG 2 a-f. Tonsillar infiltration of Langerhans cells with pale eosinophilic cytoplasm, irregular and elongated nuclei, and indistinct nucleoli with hematoxylin and eosin staining $(a, b)$. Langerhans cells show immunostaining for S100 protein and CD1a, respectively (c,d). Absence of immunoreactivity for PAX5 and CD20, respectively $(e, f)$.

Patient Consent for Publication: Written informed consent was obtained from the patient

Author Contributions: Concept - I.L.M., C.A.; Supervision - F.C., M.R., V.B.; Data Collection and/or Processing - I.L.M.; Literature Review - I.L.M.; Writing - F.C., M.R., C.A.

Conflict of Interest: The authors has no conflict of interest to declare.

\section{REFERENCES}

1. Haupt R, Minkov M, Astigarraga I, et al. Langerhans cell histiocytosis (LCH): guidelines for diagnosis, clinical work-up, and treatment for patients till the age of 18 years. Pediatr Blood Cancer. 2013;60:175-184. [CrossRef]

2. Rodriguez-Galindo C, Allen CE. Langerhans cell histiocytosis. Blood. 2020;135:13191331. [CrossRef]

3. Atalay F, Koç EA, Yıldız S. A rare presentation of langerhans cell histiocytosis tonsil infiltration: review of the literature: atypical presentation of langerhans cell histiocytosis. Indian J Hematol Blood Transfus. 2014;30(suppl 1):437-439. [CrossRef] 